\title{
A Low-Cost Arduino-based Smart Irrigation System (LCABSIS)
}

\author{
Jolan Baccay Sy ${ }^{1}$, Edward B. Panganiban ${ }^{2}$, Abdulkerim Seid Endris ${ }^{3}$ \\ ${ }^{1,3}$ School of Electrical and Computer Engineering, Kombolcha Institute of Technology, \\ Wollo University, Ethiopia \\ ${ }^{2}$ Isabela State University, Echague, Isabela, Philippines
}

\begin{abstract}
This study shows the best approach to have an effective low cost Arduino-based smart irrigation system (LCABSIS). The system is designed to allow farmers to be more efficient, to reduce labor expenses and to make reasonable use of water by utilizing the correct amount at the appropriate way. The Arduino based smart irrigation system consists of Arduino, LCD , SIM900 A, moisture sensors, an Ultrasonic sensor, a solenoid valve, and a submersible pump. The motivation of the study due to lack of vegetable supplies and the inflation rate, Since Ethiopia's economy is based on agriculture and the climatic conditions lead to a lack of rain and scarcity of water in some areas. There is a vast land that is not utilized due to the improper use of water. Also, The farmers manually turn the pump on/off whenever needed, which compels them to stop doing other works - which are also essential for them to, and thus they lose their precious time and efforts. This automatic irrigation system senses the moisture content of the soil, and the availability of water in the reservoir automatically switches the pump either to fill it to the tank or to irrigate. Appropriate use of irrigation systems is very significant because the key factor is the shortage of land allocated for water due to lack of rain, unforeseen utilization of water; as a result, huge quantities of water get wasted. Photos of the built and tested prototype, a schematic diagram of the control system, and the flowchart on which the Arduino script is developed are shown. The operation and user-interaction of the actual system are also described. Data are also tabulated and shown, along with statistical analysis. The control system program is written such that the moisture content is displayed in liquid crystal display(LCD) and send SMS.
\end{abstract}

Key words: Arduino Automated System, Moisture Sensor, Ultrasonic Sensor

\section{INTRODUCTION}

Agriculture plays a vital role in the economy of most nations. The growth of agriculture means economic development[1]. The approximate population of Ethiopia is 115,528,092 as of
15 September 2020, based on the world Meter, with a total land area of 1,000,000 km2 (386,102 sq . miles) and 21,3 per cent of the population urban $(24,463,423$ in 2020). Most of the population lives as farmers in rural areas [2].

Ethiopia is the second largest populous nation in Africa. Agriculture is the backbone of the Ethiopian economy, accounting for 41.4 per cent of the country's gross domestic product ( GDP), 83.9 per cent of total exports, and 80 per cent of all jobs in the country [3]. Farmers were faced with demanding tasks due to the restricted presence of technology. The first agricultural revolution required the advent of new technology (as tractors). This meant a dramatic shift for farmers, as they could be even more productive and move towards a technological age [4].

From the study of S. Akter, P. Mahanta, and others They develop intelligent irrigation systems based on microcontrollers. Their system uses soil moisture sensors as input, and they only determine that their system will help restrain wasteful irrigation and inadequate irrigation. This system acts as a possible remedy to the challenges of manually watering in the farm. Their design is only used of soil moisture sensor without interaction on the water availability and also the in input from the farmers if they allow the system to work or not [5].

Ethiopia has the best opportunity to develop a water management system for both irrigation and hydropower. In order to capture its full potential, it needs to overcome crucial challenges in the preparation, design, implementation and maintenance of its irrigation systems. The strongest options to be considered for the production of effective and stable food security are the expansion of irrigation systems on a variety of scales, by river diversion, the building of small dams and water harvesting mechanisms [6].

The deployment of farming emerging technologies is the necessity for advanced agricultural innovation, but it is also an important sign of the upcoming degree of agricultural progress; it will be the future path of agricultural improvement. Following the design of the farmland water irrigation process technology and the study and research of the channel management features, functionality and the 
related software architecture of the precision agriculture water irrigation systems, the actual implementation of the Internet of Things to highly effective and secure agricultural production has a major effect on ensuring the efficient use of water [7].

Nowadays, the growth in the agriculture industry is attributed to the advancement of the idea of smart farming and modernization. One of the technologies developed is the smart irrigation system. Several smart irrigation systems [8], [9] was developed. Some has established a smart irrigation system with the controlled process [10], [11], and embedded system [12]. The integration of the internet of things (IoT) to smart irrigation system were also introduced which tracks and keeps the appropriate the content of soil moisture [13] or evaluate the water needed for plants [14]. Solar energy was used in the paper of Harishankar et al. [15] to implement their developed smart irrigation system. A smart irrigation system can also be established using Message Queue Telemetry Transport protocol [16], and TINY OS focused on IRIS methods to calculate the water content of the agricultural land [17]. Smart Agriculture Irrigation System Using Raspberry Pi was developed by Chate and Rana while this paper used Arduino UNO as its microcontroller.

\section{METHODS}

The development of the Low-Cost Arduino-based Smart Irrigation System follows a four-part methodology: formulation of the required design based on sensor behavior, operational, manufacturing, and economic requirements; modeling, design, and simulation of the Arduino based control system; system test and data collection; and hardware prototype development

\subsection{System Requirements}

Ethiopia has vast natural resources, and it's known as the water tower of Africa; it has an excellent opportunity of irrigating the land resource. The government's strong political commitment and encouragement to study cost-effective and automated irrigation systems. The system is designed to help meet these requirements. The control system components are to be selected to be the cheapest possible or can be sourced from junk materials. The code for the micro-controller should be written so that it can easily be modified to suit the actual components used.

\subsection{Control System Design}

The design of the control system is illustrated by way of the LCABSIS Block diagram in figure 1. Microcontroller Arduino UNO is the major component that controls components attached to it. The components used were SIM900A, soil moisture sensor, ultrasonic sensor, LCD, submersible pump, and water solenoid valve. Its equivalent schematic diagram is shown in figure 2 .

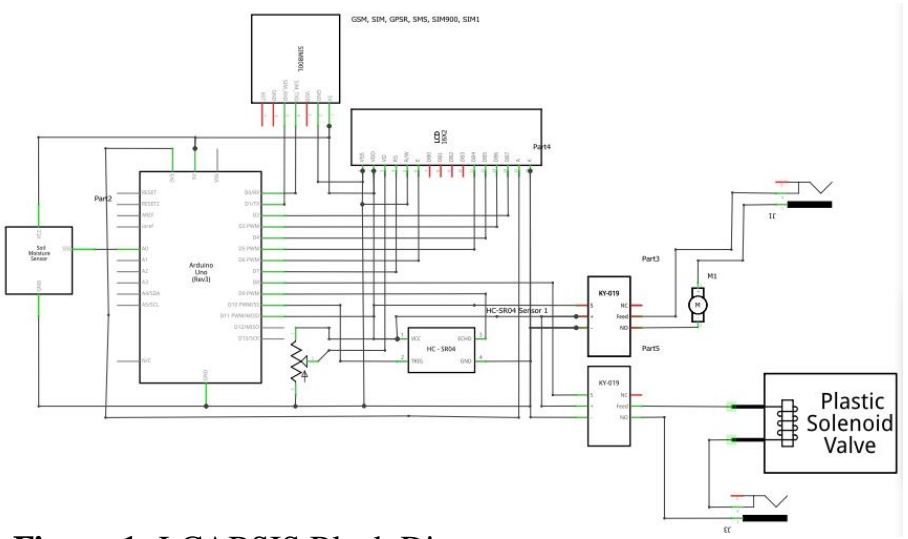

Figure 1: LCABSIS Block Diagram

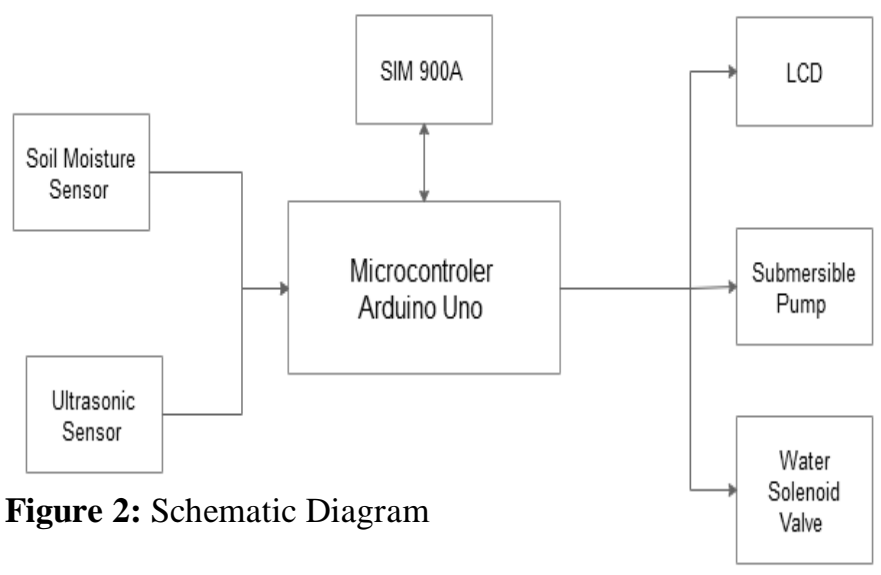

\subsection{Control System Software Modeling and Simulation}

Figure 3 is the LCABSIS control system model equivalent to the smart system developed. It shows the actual connections of the components used to have an easier guide on how the components were attached to each other.

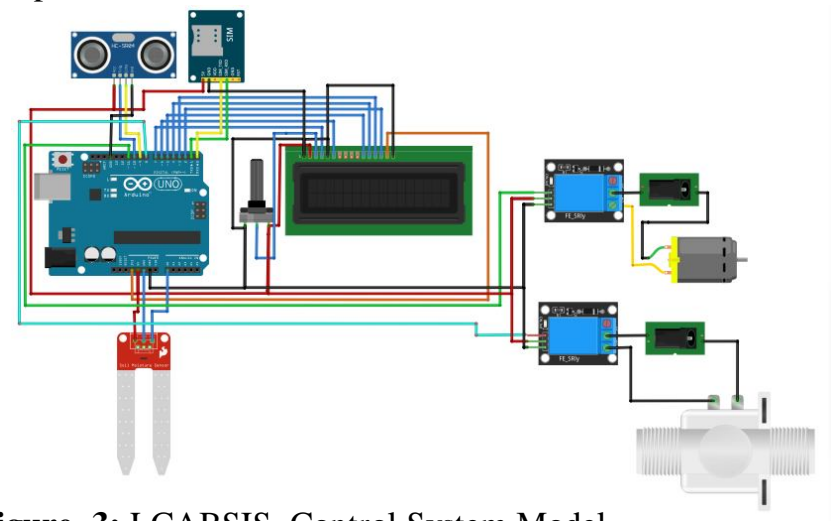

Figure 3: LCABSIS Control System Model

\subsection{Hardware Model Parts List:}

Below is the discussion on the components used in this paper.

\section{a. Main Component}

Arduino UNO [18-15] is a type of microcontroller that is based on the concept of a Microchip ATmega328P 
microcontroller that controls the input or output of the smart irrigation system.

\section{b. Soil Moisture sensor}

This sensor for the soil moisture is a system for measuring soil moisture content. It comprises of an attaching probe mounted in the soil. it is utilized to detect soil moisture and transmit impulses to the controller when the moisture level exceeds the specified level.

\section{c. GSM modem}

GSM SIM 900 A [18] is used to transmit information From distant regions such as one location to the same location or another location. Send a message to the user about the soil moisture content status, either to acknowledge that the engine is automatically turned on or simply to ignore it.

\section{d. Solenoid valve}

The solenoid valve is an electric powered system comprised of an energizing coil and a soft piece of iron with a valve that cuts or supplies the fluid. When the coil is supplied, it energizes and pushes the valve, and the valve opens and the water flows. When the coil is de-energized, the valve closes automatically due to the spring movement and cuts off the water supply. $T$ he function of the solenoid valve will be automatic as soon as the water level in the container exceeds the minimum reference level.

\section{e. Relay}

Relay is also an electrical device consisting of an two $\mathrm{NC}$ and NO contacts, operating coil. NC is configured as normally closed and NC is normally open contacts. If the coil is not supplied, there is no change in the contact position. When the coil is supplied, NO closes, and NC opens. It remains the unchanged until the coil is in powered state.

\section{f. Water Pump Submersible}

This is used to pump or get water from the source like container and is directly connected to the distribution pipe or host.

\section{g. Ultrasonic Sensor}

This is an electronic component that can determine the distance to an item by using a sound wave. It calculates distance by sending a sound wave to a particular frequency and by listening to the sound wave rebounding. It is used to calculate the water depth in the container.

\section{h. Liquid Crystal Display(LCD)}

In order to create a visible image, the electronic display module uses liquid crystal. In this paper, LCD will display the moisture content of the soil, the water level of the container, and the time the motor is running.

\subsection{Flowchart}

The Arduino Uno script is based on the flowchart shown in Figure 4. This serves as the detailed steps in the operation of the low cost and Arduino-based smart irrigation system. This is also a guide for the researchers to come up with a desirable output.

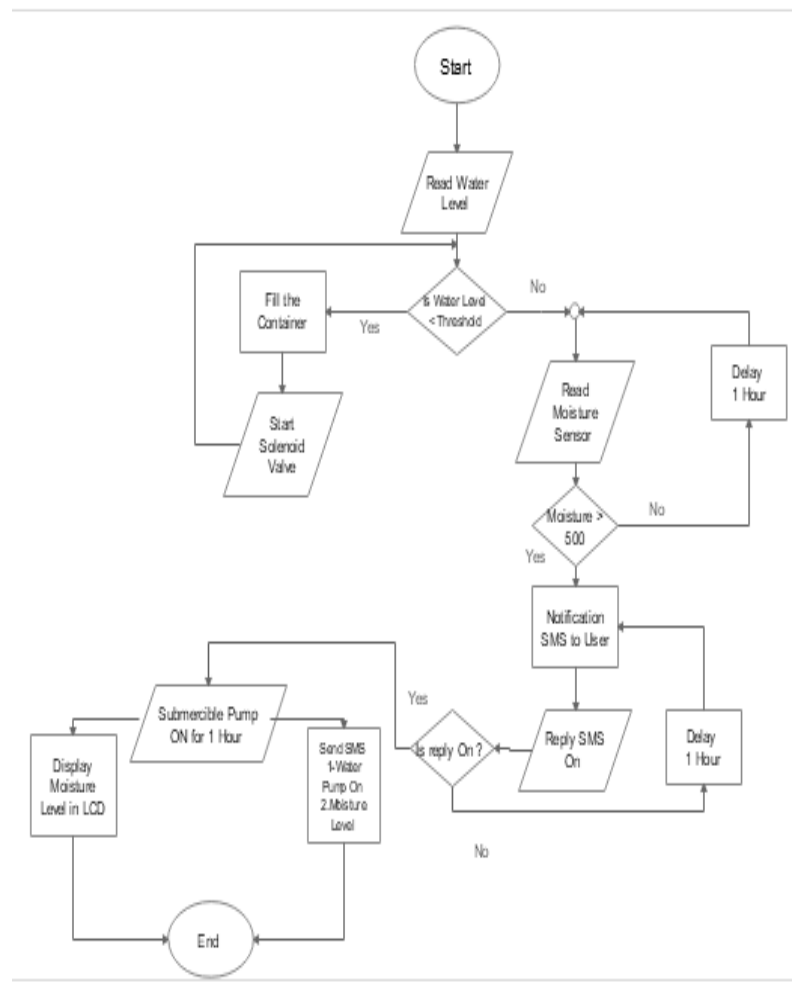

Figure 4: Process Flowchart

\subsection{Hardware Prototype Development}

The developed hardware prototype for this paper titled "Low-Cost Arduino-based Smart Irrigation System" is shown in figures $5 \mathrm{~A}, 5 \mathrm{~B}$, and $5 \mathrm{C}$ together with its components. Figure $5 \mathrm{~A}$ is the prototype implementation; figure 5B shows how the moisture sensor was tested, while figure $5 \mathrm{C}$ is the complete set-up of the established smart irrigation system.

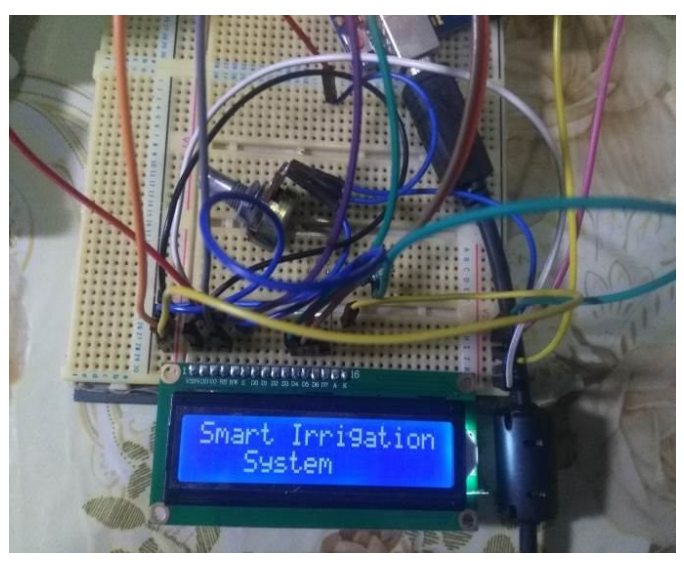

Figure 5A: Control System Prototype Implementation 


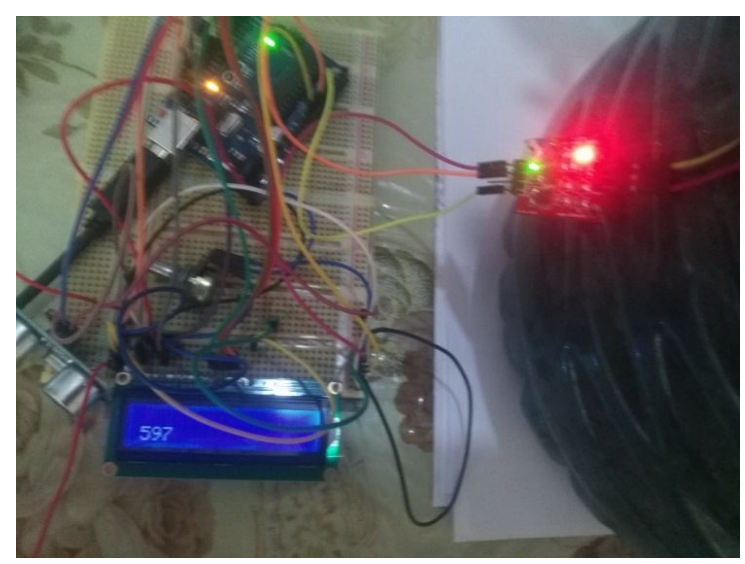

Figure 5B: Moisture Sensor Testing

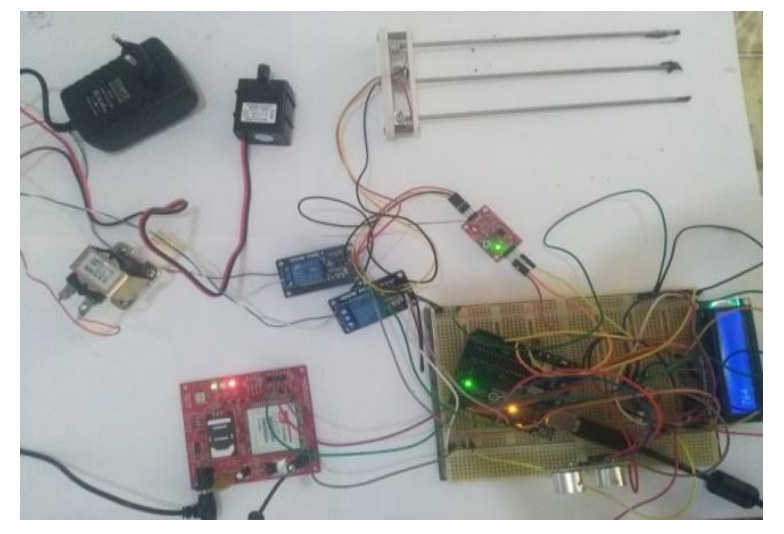

Figure 5C: Complete Setup Smart Irrigation System

\section{RESULTS AND DISCUSSION}

\subsection{System Tests and Data Collection}

Throughout the number of iterations undertaken in the development of the LCABSIS, from hardware prototype, a series of similar tests are conducted. There are 7 test cases on the system, as illustrated in table 1.

Table 1: System test cases

\begin{tabular}{|l|}
\hline 1. Ultrasonic sensor (Water Level) at minimum water level \\
- The solenoid valve motor automatically on \\
\hline $\begin{array}{l}\text { 2. Ultrasonic sensor (Water Level) at maximum water level } \\
\text { - The solenoid valve motor automatically OFF }\end{array}$ \\
\hline 3. Soil Moisture Sensor < 500 Submersible pump is OFF \\
\hline 4. Soil Moisture Sensor > 500 Submersible pump is OFF \\
\hline $\begin{array}{l}\text { 5. Sim } 900 \text { A Send Data to User when the soil moisture } \\
\text { sensor is > 500 }\end{array}$ \\
\hline 6. Sim 900 A Received Data to User to ON the motor \\
\hline $\begin{array}{l}\text { 7. LCD displayed the Moisture sensor and duration time the } \\
\text { motor is running }\end{array}$ \\
\hline
\end{tabular}

\subsection{Test comparison using Control System Hardware Model Tests and Hardware Prototype Tests}

The tests conducted and the results for 1) Control System Hardware Model Tests and 2) Hardware Prototype Tests are similarly based on findings during the experiments

The results are summarized, as shown in Table 2.

Table 2: Summary of System Responses under the Different Test Cases

\begin{tabular}{|c|c|c|c|}
\hline $\begin{array}{l}\text { Test } \\
\text { Case }\end{array}$ & $\begin{array}{c}\text { System } \\
\text { Description }\end{array}$ & $\begin{array}{l}\text { Control } \\
\text { System } \\
\text { Hardware } \\
\text { Model }\end{array}$ & $\begin{array}{c}\text { LCABSIS } \\
\text { Prototype }\end{array}$ \\
\hline 1 & $\begin{array}{c}\text { Ultrasonic sensor } \\
\text { (Water Level ) at } \\
\text { minimum water } \\
\text { level - The } \\
\text { solenoid valve } \\
\text { motor } \\
\text { automatically on } \\
\end{array}$ & Correct & Correct \\
\hline 2 & $\begin{array}{c}\text { Ultrasonic sensor } \\
\text { (Water Level ) at } \\
\text { Maximum water } \\
\text { level - The } \\
\text { solenoid valve } \\
\text { motor } \\
\text { automatically OFF }\end{array}$ & Correct & Correct \\
\hline 3 & $\begin{array}{c}\text { Soil Moisture } \\
\text { Sensor < } 500 \\
\text { Submersible pump } \\
\text { is OFF }\end{array}$ & Correct & Correct \\
\hline 4 & $\begin{array}{c}\text { Soil Moisture } \\
\text { Sensor > 500 } \\
\text { Submersible pump } \\
\text { is OFF }\end{array}$ & Correct & Correct \\
\hline 5 & $\begin{array}{l}\text { Sim } 900 \text { A Send } \\
\text { Data to User when } \\
\text { the soil moisture } \\
\text { sensor is }>500\end{array}$ & Correct & Correct \\
\hline 4 & $\begin{array}{c}\text { Sim } 900 \mathrm{~A} \\
\text { Received Data to } \\
\text { User to ON the } \\
\text { motor }\end{array}$ & Correct & Correct \\
\hline 6 & $\begin{array}{l}\text { LCD displayed the } \\
\text { Moisture sensor } \\
\text { and duration time } \\
\text { the motor is } \\
\text { running }\end{array}$ & Correct & Correct \\
\hline
\end{tabular}


Jolan Baccay Sy et al., International Journal of Emerging Trends in Engineering Research, 8(9), September 2020, 5645 - 5650

\section{CONCLUSION}

In this paper, a low-cost smart irrigation system based on a microcontroller (Arduino) was developed. The microcontroller circuit has been made with few components, and the circuit is highly reliable. This circuit consisted of Arduino UNO, GSM/GPRS SIM 900 A module, Ultrasonic Sensor, Soil Moisture sensor, relay, Water Solenoid Valve ( 12 Volts), Liquid Crystal Display (LCD), Submersible motor Pump (12 Volts). This system received data from the ultrasonic sensor for the water level in the container and also take data from soil moisture sensors to soil irrigation, which aims to save water and to irrigate the exact needed amount of water. This research is a potential solution to solve the problem of improper use of water and save labor costs. This study showed that this low-cost Arduino-based smart irrigation system needed less water and less time compared to conventional irrigation system. It has improved irrigation production. The sensor-based irrigation system is the most efficient system and runs automatically without assistance. This makes the device more effective and comfortable. The key drawback of this research is that it is being evaluated on a small scale; future researches are essential for large-scale agriculture.

\section{References}

[1] K. K. Monisha, "Smart irrigation system using Arduino Uno," 2018.

[2] "Ethiopia Population (2020) - Worldometer." .

[3] "Agriculture in Ethiopia - Infomineo.".

[4] A. C. Gilarranz, S. Altares, and M. Loizu, "Intelligent Irrigation System Based On S3C6410," Revista de la Facultad de Ingeniería, no. 1, pp. 2-7, 2016.

[5] S. Akter, P. Mahanta, M. H. Mim, R. Hasan, and R. Uddin, "Developing a Smart Irrigation System Using Arduino," International Journal of Research Studies in Science, Engineering and Technology, vol. 6, no. 1, pp. 31-39, 2018.

[6] M. Kassa and T. G. Andualem, "Review of Irrigation Practice in Ethiopia, Lessons from Israel," Irrigation \& Drainage Systems Engineering, vol. 9, no. 1, pp. 1-6, 2020.

[7] P. Naik and K. Katti, "Automation Of Irrigation System Using IoT," 2018 Fourth International Conference on Advances in Electrical, Electronics, Information, Communication and Bio-Informatics (AEEICB), vol. 8, no. 1, pp. 77-88, 2018.

[8] S. Darshna, T. Sangavi, M. Sheena, A. Soundharya, and S. Desikan, "Smart irrigation system," IOSR Journal of Electronics and Communication Engineering (IOSR-JECE), vol. 10, no. 3, pp. 32-36, 2015.

[9] A. Tyagi, D. J. P. Navani, N. Gupta, R. Tiwari, and A. Gupta, "Smart irrigation system," IJIRST -International Journal for Innovative Research in
Science \& Technology $\mid$, vol. 3, no. 10, pp. 9-12, 2017.

[10] C. Kumar Sahu and P. Behera, "A low cost smart irrigation control system," in 2nd International Conference on Electronics and Communication Systems, ICECS 2015, 2015, pp. 1146-1151.

[11] M. D. Kumar Roy and M. M. Hassan Ansari, "Smart Irrigation Control System," International Journal of Environmental Research and Development, vol. 4, no. 4, pp. 371-374, 2014.

[12] K. K. Namala, A. V. Krishna Kanth Prabhu, A. Math, A. Kumari, and S. Kulkarni, "Smart irrigation with embedded system," in IEEE Bombay Section Symposium 2016: Frontiers of Technology: Fuelling Prosperity of Planet and People, IBSS 2016, 2016.

[13] S. Rawal, "IoT based Smart Irrigation System," International Journal of Computer Applications, vol. 159, no. 8, pp. 7-11, 2017.

[14] S. Hwang, "Monitoring and Controlling System for an IoT Based Smart Home," in 2017 2nd IEEE International Conference On Recent Trends in Electronics Information \& Communication Technology (RTEICT), 2017, pp. 815-819.

[15] S. Harishankar, R. S. Kumar, K. P. Sudharsan, U. Vignesh, and T. Viveknath, "Solar Powered Smart Irrigation System," Advance in Electronic and Electric Engineering, vol. 4, no. 4, pp. 341-346, 2014.

[16] R. K. Kodali and B. S. Sarjerao, "A low cost smart irrigation system using MQTT protocol," TENSYMP 2017 - IEEE International Symposium on Technologies for Smart Cities, 2017.

[17] P. Alagupandi, R. Ramesh, and S. Gayathri, "Smart irrigation system for outdoor environment using Tiny OS," in 2014 International Conference on Computation of Power, Energy, Information and Communication, ICCPEIC 2014, 2014, pp. 104-108.

[18] E. B. Panganiban, "Automated hazardous gas detecting robot using wireless sensor networks with GSM-SMS alert and fire control system for households," International Journal of Advanced Trends in Computer Science and Engineering, vol. 8, no. 3, pp. 804-809, 2019.

[19] E. Panganiban, B. B. Abad, and M. Caranguian, "Aluminum can to WiFi trading system with metal can and plastic bottle collector and monitoring system," International Journal of Emerging Trends in Engineering Research, vol. 8, no. 7, pp. 3639-3644, 2020.

[20] E. B. Panganiban and J. C. Dela Cruz, "RFID-Based Vehicle Monitoring System," in HNICEM 2017 9th International Conference on Humanoid, Nanotechnology, Information Technology, Communication and Control, Environment and Management, 2017, pp. 1-6.

[21] E. B. Panganiban, "Rainfall Measurement And Flood Warning Systems : A Review," International 
Journal of Scientific \& Technology Research, vol. 9, no. 03, pp. 244-254, 2020.

[22] E. B. Panganiban et al., "Real-Time Intelligent Healthcare Monitoring and Diagnosis System Through Deep Learning and Segmented Analysis," IFMBE Proceedings, vol. 74, pp. 15-25, 2019.

[23] M. M. Caranguian, B. B. Abad, and E. B. Panganiban, "Tilapia fishpond monitoring system with fishkill prevention," International Journal of Emerging Trends in Engineering Research, vol. 8, no. 7, pp. 3478-3482, 2020.

[24] B. B. Abad, M. M. Caranguian, and E. B. Panganiban, "IoT-based compact-matic drinking water filtration machine," International Journal of Emerging Trends in Engineering Research, vol. 8, no. 7, pp. 3887-3892, 2020.

[25] E. B. Panganiban, "Microcontroller-based Wearable Blood Pressure Monitoring Device with GPS and SMS Feature through Mobile App," International Journal of Emerging Trends in Engineering Research, vol. 7, no. 6, pp. 32-35, 2019. 